\title{
PROCESS OF GOVERNANCE IN ADVERTISEMENT REGULATION IN THE UNITED ARAB EMIRATES
}

\author{
Beena Salim Saji', Reshma Das John", Malini Nair"ll, Dr. Roudaina HoujeirlV
} Abu Dhabi Men's College, Abu Dhabi, United Arab Emirates

\section{ABSTRACT}

United Arab Emirates has grown in great leaps as a country which can claim very high achievements in different sectors of economy such as real estate, education, banking, retail, trading, telecommunications, airline and tourism, as well as in many other spheres. Complementing these developments, is a large of advertisement activities which are aimed at attracting and retaining customers who are very diverse in nature. The advertisement industry hence is booming as the competition between companies is getting more and more aggressive. It is safe to conclude that with so many advertisements, competing for the attention of the young Emirati population as well as the working expat community, there is significant pressure on advertisement agencies to make their advertisements more captivating. This may be leading to an exaggeration of values that the organization can give through their products and services, and may use language that may become just more memorable than accurate (AI Tamimi, 2013). As in the other countries, there is self-regulation for advertising in UAE, but there is also complex set of regulations that incorporate different laws. This paper is an attempt to explore the methods and processes adopted by advertising agencies or organizations that create advertisements, to ensure compliance with these laws. The study used interviews with officials of advertising agency and government organisations which control advertisements, such as the ministry of information and municipality sections dealing with advertisements, to understand the processes and methods of ensuring governance in advertising. The study adds value to the existing knowledge of advertisement governance and gives insights into the UAE perspective.

\section{JEL CLASSIFICATION \& KEYWORDS}

- M3 M380 - ADVERTISING — GOVERNANCE - ADVERTISING GOVERNANCE ॥ SELF-REGULATION

\section{INTRODUCTION}

The United Arab Emirates was established on December 2, 1971 and is a federation of seven emirates: Abu Dhabi, Dubai, Sharjah, Ajman, Umm al-Qaiwain, Ras al-Khaimah and Fujairah. United Arab Emirates is one of the most emerging economies among the developing countries. The growth is fuelled by government spending in key infrastructure areas of oil and gas exploration and processing, real estate development and construction, as well as consumer banking, finance and retail sectors. The growth also makes room for a host of marketing activities to sustain and encourage the demand for various products and services and to encourage healthy competition among the players in the market. Among all the marketing weapons, advertising is renowned

' beenasaji.s@gmail.com

" rjohn@hct.ac.ae;

III mnair@hct.ac.ae;

IV rhajeer@hct.ac.ae

www.journals.cz for its long long-lasting effect on viewer's mind, as its exposure is much broader. Advertising, like other promotional tools, aims at getting messages across to customers about products offered by an organization. Consequently, effectiveness of advertisement is assessed in terms of the level of awareness they create among customers.

This study examines the process of advertising governance in United Arab Emirates. The main actors of advertising governance are the organizations, advertising agencies, and the legal and judiciary policing systems of country.

UAE being a country which zealously follows and preserves its religious traditions and cultural values, there are very little opportunities for newspapers or other media to publish any content without looking into the culture, traditions and governance established by the rules and regulations of the systems in the country.

The study identified that UAE advertising agencies and organizations follow a process of governance through creating regulations and checks related to advertisement related messages reaching their customers,before an advertisement is released in the public domain. The continuously evolving regulations and rules can be seen as a growth-oriented country's actions in controlling and regulating a rapidly growing business and service industry of the country.

A rapidly growing economy of a young country has its own control and regulation process as it is a learning curve for the decision makers and rulers of the country. They have to make the right decision which will promote the use of advertising as a means to spur the demand within the economy, while ensuring that the messages conform to the cultural, moral and religious values held up by the nation. UAE is a typical example for this dichotomy where there is a flux of international, multinational and national organizations competing in the same space for the attention of around 8 million dwellers of their country. United Arab Emirates is a country which has an extra-ordinarily large number of expat dwellers who have come here, attracted by the business and job opportunities that the country has to offer. The population of UAE nationals is only $20 \%$ of the whole population and hence the government plays a larger role in ensuring that their culture and traditions remain intact and protected from the rapidly growing market economy and challenges. Advertising is one major area that government needs to control as the messages coming through many media can affect the people and economy in myriad ways. The Government of UAE has thus been trying to develop, implement and sustain best practices in advertisement governance among agencies and organizations to ensure the content and themes of the messages remain within a domain of acceptance set up by regulatory systems and social norms. 


\section{Rationale for the Reseach}

The UAE advertising spend has been growing in leaps and bounds and accounted for a 33 percent share of the GCC's total advertising spend which was estimated at $\$ 4.8$ billion in 2012. It retained its number one position as the print media dominance went as high as 71 percent share of the overall market (Issac, 2013). According to a report carried out by OOXmonitor, a web-based service that provides advertising monitoring in the Middle East, digital advertising spend grew by 12.6 per cent in the UAE compared to 5.3 per cent in Saudi Arabia in 2012. The UAE accounts for 47.1 per cent of GCC online ad spend. (Issac; 2013)

Contrary to the global trends, newspaper circulation of UAE is the highest with a growth rate of 4.8 per cent in the Middle East and grew by 3.5 per cent in Asia, the Kuwait Financial Centre, Markaz said in its GCC Media report (Issac, 2013). Markaz (Gulf news, 2014) noted that the media industry landscape is also changing rapidly as a consequence of technological advancements and changing consumers habits. "The digital media is growing in influence and effectiveness. Presently, the digital media captures 18 per cent of global media share of ad spending, which is expected to grow to 20 per cent by 2014."According to a report carried out by OOXmonitor, a web-based service that provides advertising monitoring in the Middle East, digital ad spend grew by 12.6 per cent in the UAE compared to 5.3 per cent in Saudi Arabia in 2012. The UAE accounts for 47.1 per cent of GCC online ad spend.

A clear pattern is starting to show up since early 2013 - if the first-half of last year saw steady increases in spending, there was a sharp spike in the second-half as build-up towards the confirmation of Dubai as the host city for World Expo 2020 in late November. December sparked a celebratory round of advertising highs as marketers and the local ad industry got the confirmation that the upturn was well and truly on. The first quarter of 2014 confirms the bullishness. (Gulf News, 2014)

Traditional media continues to hold its own in the UAE's ad mix; newspapers pulled in $\$ 227$ million for a steady 57 per cent share, while magazines accounted for $\$ 58$ million (15 per cent share of the overall). Television commercials fetched $\$ 31$ million in the first quarter, representing 8 per cent of the total. The share of outdoor media, at $\$ 59$ million, was also put at 15 per cent. ("Currently both multinational brands as well as strong local brands are spending, though there are variations in the individual spending patterns," said Mahesh Sundaresan, CEO at Ikon Advertising \& Marketing. "MNC brands will always consider media that delivers reach across markets, such as pan-Arab television. As for digital, it is registering strong growth driven by both MNCs as well as local brands."Where we can see clear spike in ad spend is in retail, services and FMCG (fast moving consumer goods) which is in line with Nielsen's UAE consumer Confidence Index for Q1-2014 which is positive. While real estate spends have gone up, these have been on very select projects." (Gulf news, 2014)

\section{Advertisement Governance Conceptualizations and Research}

According to Pollay (1986), and Frith and Frith (1990), foreign advertisers are accused of imposing a western advertisement culture in domestic markets, which may threaten the indigenous culture of the domestic markets. According to Frith and Frith (1990) consumer culture is a western social standard that encourages consumption and individualistic competition for materialistic satisfaction, which is in conflict with the collective, non-materialistic values of the developing counties of the world. One such threat to the local cultural values could be the foreign advertisement which may project different values, in conflict with the existing tradition and values of the host country.

Emotional responses aroused by advertisements is usually censored at the media end or any farther approval required goes to the state administrative and regulatory media authority for final approval. This has been a process which China was using for protecting the people from excessive consumerism and to protect their cultural values (Louisa $\mathrm{Ha}$, 1996). Miracle and Nevett (1987) have researched into role of private industry trade agencies in controlling the content and regulations related to advertisement. Bodewynn (1985) found that sometimes these self-governed private advertising agencies can be like private government and use their power to control other advertisement agencies of the country.

Various studies have examined the effectiveness of advertising in the past decade. The common measures of advertising effectiveness include ad recall, ad recognition, brand awareness, clicks or click through rate, attitude towards the ad and the brand, and purchase consideration.

Definition of Advertising

Advertising, sales promotion and public relations are masscommunication tools available to marketers. As its name suggests, mass communication uses the same message for everyone in an audience. The mass communication tools trade off the advantage of personal selling, the opportunity to tailor a message to each prospect, for the advantage of reaching many people at a lower cost per person (Etzel et al., 1997). Today, definitions of advertising flourish. Wemight define it as communication process, a marketing process, an economic and social process, a public relations process or an information and persuasion process (Arens, 1996). Dunn et al. (1987) viewed advertising from its functional perspectives, hence they define it as a paid, non-personal communication through various media by business firms, non-profit organization, and individuals who are in some way identified in the advertising message and who hope to inform or persuade members of a particular audience. Morden (1991) is of the opinion that advertising is used to establish a basic awareness of the product or service in the mind of the potential customer and to build up knowledge about it. By its definition Advertisement is a unidirectional and paid form of communication that is used to disseminate the product or services information, (Wells, et al. 1994). Companies invest heavily on advertisement campaigns. An estimate of spending on advertisement in 2005 around the world is $\$ 300$ Billion (Laczniak, \& Ramaswami; 2001). The primary focus of advertisement is to enhance the business profitability therefore companies ignore many social aspects while designing an advertisement campaign. In contemporary marketing practices, Advertisement means to create a need of the product in the mind of the consumers to influence its mind in a way that he feels thrust for that product weather he really needs that product or not (Singh, 1998).

Kotler (1988) sees advertising as one of the four major tools companies use to direct persuasive communications to target buyers and public noting that "it consists of nonpersonal forms of communication conducted through paid media under clear sponsorship". While writing on advertising nature and scope, Etzel et al. (1997) succinctly capture all advertising as having four features: (i) A verbal and or visual message, (ii) A sponsor who is identified; (iii) Delivery through one or more media, (iv) Payment by the sponsor to the media. 
Advertising has been defined as 'any paid form for nonpersonal presentation and promotion of ideas, goods or services by an identified sponsor' (American Marketing Association, quoted in Bennet, 2000: 117) and more narrowly as 'any human communication intended to persuade or influence buyers in their purchase decisions' (Cheng, 1996: 74). In conclusion, it can be concluded that "advertising then consist of all the activities involved in presenting to an audience a non-personal, sponsoridentified, paid-for message about a product or organization". Those views of Etzel et al. (1997) coincide with the simple but all-embracing definition of Arens (1996). For instance, while Davies states that "advertising is any paid form of non-personal media presentation promoting ideas/concepts, good s or services by an identified sponsor. Arens (1996) expressing almost the same view describes advertising as "the personal communication of information usually paid for and usually persuasive in nature about products (goods and services) or ideas by identified sponsors through various media".

\section{Regulations for Advertisements in UAE}

The United Arab Emirates has its own rules and regulations specific to advertisements. Advertisements are not regulated by a single regulation; they are regulated by numerous laws such as the Printing and Publication law, National Media Council regulations and Cyber crime law and laws governing consumer protection and commercial activities particularly in relation to anti-competitive practices and illegal monopolies. Generally, advertisements must comply with the relevant advertising standards and consumer protection legislation in each jurisdiction in which they are published.

Furthermore, in this region, advertisements should be sensitive to the cultural outlook and tolerances of the target audience in addition to the legal framework governing the dissemination of advertising content. Producers and advertisers will always focus on what they want to convey to the people throughout the content of the advert - they will want to deliver their idea in a creative way to attract attention. It is important to remember that, though advertisers have freedom to be creative, there are bounds imposed by these laws and local culture.

According to Haque et al., (2010), 'marketers need to observe the cultural traits, environments, norms, beliefs, and values of a specific country or region to attain an understanding of whether their future behaviors will be perceived as ethical'. That is, when doing marketing for the products, cultural, religious, and social sensitivities of the people targeted should be taken into account by placing advertisements to effectively win their hearts and create market charisma. We are in an era where advertising is redefining itself every second day, where regulations are questioned on the basis of its relevance in current scenario every hour and a new advertisement is released across various platforms every second in some part of the country (Ambwani, 2015).

\section{Research Questions}

What is the process that organizations go through to ensure advertisement governance in UAE?

What are the governmental and legal compliance systems related to an advertisement messages?

\section{Methodology}

The present research focus on an exploratory research approach to understand the processes used by UAE organizations and multinational organizations as well as advertising agencies and media in complying with the advertising regulatory mechanisms in UAE. Therefore, in-depth interviews with advertising agencies and marketing managers are used as a major source of data for the study. National Media Council website review is also used to understand the process of advertisement regulation in United Arab Emirates.

A pool of questions was made to prepare an interview schedule. Content analysis of the interviews was done to develop a conceptual understanding of the advertisement governance process being followed within organizations as well as by the regulatory authorities in United Arab Emirates. The challenges and corrective suggestions may also be included to identify areas of change and improvement in the existing processes and governance related to advertising in UAE.

\section{Interview Analysis and Discussion}

At a very basic level, advertisements are tools to call attention of the public to specific products or services offered by an entity (Al Tamimi, 2013). While the primary duty of the advertiser is to make the advertising attractive and informative to the consumers, they have to do it in such a way as to ensure that the content is within the limits specified by the laws and regulations and the religious and cultural norms of the UAE. In the UAE, the advertisements are regulated by numerous laws such as the Printing and Publication Law, Healthcare advertising regulations, the regulations of the National Media Council, laws governing consumer protection and commercial activities etc. (Al Tamimi, 2015)

Interview 1

One of the experts interviewed for this study was the Director of Client Servicing in one of the leading advertising agencies in UAE with its headquarters in Dubai, and operations in the GCC, MENA and Russia. An in-depth interview approach was used, where a set of semi-structured questions, with further in-roads explored on several tangents, was used to elicit detailed answers about the process of advertising development with regard to the type of governance used by the agency. The Director was asked to explain the process of advertising governance employed in UAE, with reference to process of the creating and running an advertising campaign.

The process of creating a simple advertisement or a large advertisement campaign is quite complex and involves several steps. The major stakeholders identified in the process are: the advertising agency, the client, the marketing research companies, the regulatory bodies and the media. Every advertising campaign starts with the receiving of the brief from the client. While the advertising brief of a large campaign or a big company may be quite comprehensive, running into several pages and covering all aspects of the campaign such as competitive analysis, advertising objectives, brand positioning, advertising effectiveness etc., the client brief for a regular-run advertisement or a small print advertisement, may be as informal and brief as a telephonic discussion.

Once the brief from the client is obtained, the client servicing department or team of the advertising company enters into detailed discussions with the client, discussing and finalizing the objectives of the advertising campaign. At this stage, the services of a marketing research company may be availed of, especially if the product is new, or the advertising campaign is new or on a large-scale. The final brief is then handed over to the creative department. The client servicing and creative teams go over the requirements and the client servicing ensures that the objectives are clear to the creative 
team. It is then the task of the creative team to come up with ideas to convey/achieve the objectives of the client in the most effective way to reach the target audience.

The process of ensuring that the advertising content complies with the rules and regulations of UAE, as well as confirming that the content conforms to, and respects the culture, values and religious beliefs of the target audience as well as the wider publics, is largely a self-governed one. At each stage of the advertising development, the advertising agency takes efforts to ensure that the content conforms to the established and accepted norms in the UAE. The client usually plays an important part in ensuring this as well, as the client brief documents and discussions usually specify the content they are expecting. They also enter into the picture while the creative content is ready to be looked at, and confirm that this is what they want.

There were no major differences observed in the advertising process for government and private clients, however, it was mentioned that government clients at times specifies the nature of the content, especially visual content, that should be used or not used in the advertising. Thus the process of adhering to the guidelines given becomes that much more clearer, and hence easier, while developing the advertising content.

The content developed for UAE is almost always suitable, and hence used without major changes, in the other GCC nations, where similar products/services are sold. However, for the markets in Saudi Arabia and Iran, considerable changes are made, or even different content developed, to ensure that the stricter cultural and religious norms and values are respected. An interesting paradox was observed that advertisers who use TV as the medium can sometimes get away with content that is not strictly within the bounds of acceptability due to the fact that most of the TV Channels popular in UAE have their headquarters/broadcasting centers abroad. However, it was further observed that most of these TV channels do have their own content-screening methods, as was recently shown when the recent advertising campaign by a leading luggage brand was taken off the air by a popular TV network, on grounds that it showed teenagers who were not dressed not appropriately enough for the UAE culture.

Interestingly, it was observed that while the importance of digital media is growing, currently, television still commands the major share of advertising in terms of volume and advertising spend. This is due to the fact that consumer surveys show that TV still commands the top slot for viewership, and consequently has the largest advertising reach. The other popular advertising vehicles in UAE are print, outdoor, radio and digital media. The advertising agency explored, has a separate digital division, which deals with the advertising on internet-related media.

That the process of censuring of the advertising content is mostly from the stakeholders of the agency and the client, was borne out by the fact that the expert interviewed, with nearly a decade of experience in a senior position within the UAE, was unaware of the existence of the advertising standards of UAE. The effectiveness of this self-governance is evident from the fact that this agency has never had any issues with the content in any of their advertising till date, in spite of the fact that a majority of their advertised products belong to the cosmetics and body care categories. However, on the question of the standards being followed, an important point noted was that the standards laid down by the international body AAA was quoted as being this advertising agency's basic reference for codes of conduct, regarding process and content.

www.journals.cz
There is, however, an area where the content is screened and approved by an external governmental body - this is in the case of advertising of pharmaceutical and healthcare products. In the case of these products, the final advertising content developed should be submitted to the Ministry of Health and approval sought. (UAE Cabinet Decision No.7 concerning health advertisements (UAE Cabinet Resolutions, n.d.) Once approved, the Ministry issues a reference number which is printed on the advertisement. It is noted that the approval given is not issued for a period of time or for a particular product, but rather for each advertisement, and is therefore, very much content-based.

Interview 2

Another expert interviewed for this study is the Legal Head of one of the leading Publication Houses in the UAE. The interviewee was queried regarding the legal requirements to run an advertisement in the UAE and the guidelines followed thereof.

According to him, the advertisements that are produced, placed or distributed within the UAE or imported into the UAE must abide by the National Media Council Resolution of Advertising Standards, Resolution No. 35 of 2012 (the "National Standards"). These are very wide in scope and cover compliance related to social and religious norms, and political and international relations. The National Standards defer the control and regulation of specialized advertising related to health, promotional campaigns, real estate, educational institutions, or securities or financial services to the respective regulatory authority of those sectors.

In addition to the National Standards, the content of all advertisements that are printed and distributed through visual media in the UAE is governed by the Publications and Publishing Law, Federal Law No. 15 of 1980 (the "Publishing Law"). The Consumer Protection Act also plays a vital role in governing the ethics of advertising in the UAE. The Executive regulation to this act provides that consumers have a right to be provided with facts that assist them in proper purchases and consumption. In addition to this, the Suppression of Fraud Executive Regulation addresses commercial statements whether made directly or indirectly. Contravention of the Fraud may expose an offending advertiser to both a fine and imprisonment. Also, in addition to the application of the above mentioned laws the Commercial Transactions Law provides protection to competitors that may be affected by misleading advertising.

The advertiser/client, the producer/advertising agency and the publishing/media are the major stakeholders and shall bear the legal responsibility and consequences of delivering as per the claims related to promises, guarantees, pledges and compensations mentioned in the advertising. The laws do not directly distinguish between Arabic and English Advertising. However, with reference to Article 5 of NMC regulations (Siassos, \& Saleem,2013), the regulations are applicable to all media institutions and do not distinguish between private and government advertising agents.

In some jurisdictions, such as for example, the UK, advertising governance is primarily done through independent self-regulating bodies, as well as through specific legislation. In the UAE, there is no such selfregulating body and advertising is regulated through a combination of provisions drawn from laws focusing on the protection of consumers on the one hand and the activities of businesses that may constitute unfair competition on the other.

Once the producer has made an advertisement it goes back to the client for approval and then it is sent to the publishing 
media. The publishing media does their own scanning to ensure that advertisement is within compliance limits of regulatory authorities. But the main responsibility for this lie with the advertisement agency who produced the same advertisement. But publishing agencies in print, audio or visual media is equally vigilant about the content of the message distributed through the advertisement and ensure that it is within the acceptance level of the cultural and other regulatory mechanisms within the country.

The process that organizations go through in advertising governance is given in Figure 1: Work Flow of Advertising Governance in the UAE.

\section{CONCLUSION}

In conclusion, the National Media Council (NMC) follows several law and articles to ensure that the content of advertisement emphasize respect of national, religious, cultural and social values. (Article 2, Law 35 of NMC, 2012). In UAE and GCC there is high emphasis on religious and cultural values and it does affect the national and regional spirits of the country. With larger number of expatriate population, the UAE tries to create a conducive cosmopolitan atmosphere, but at the same time is vigilant in ensuring that the national youth do not get affected by any undesirable content in advertisements. The NMC also tries to put a curb on international advertisements shown here, before they enter the UAE market space. The Council does put emphasis on the protection of consumer rights and there is an article in the law that would punish the publisher, producer or client if they are unable to deliver the promises in the content. Hence the role of publishing houses and producer of advertisements/ advertising agency is equally important. The publishing houses and media advertising agencies enter into a separate contract with the client to ensure their protection in any case of legal non-compliance in content by the client. But at the same time, the National Media Council and their law and articles are strong enough to lead to even a shut-down of any publishing house or advertising agency if there is a noncompliance found in advertising content. Hence advertising agencies/ production houses and publishing- print, audio or visual - do a high level of self-regulation to protect themselves from any punitive actions from the government. The National Media Council also ensures protection of intellectual property in any sort of advertising content.

The role of legal councils and advertising agency officials and publishing house legal and advertisement directors are thus prominent in the self-regulation of advertising process in the United Arab Emirates as of now. The National Media Council usually interferes when any form of consumer protection case is brought to their attention in relation to advertisements or when any unsuitable advertisement content come to their attention. The National Media Council expects advertisers, advertisement agencies and publishing house to be vigilant and create and publish advertisement within the federal laws and articles in UAE which may affect an effective performance of advertisement in UAE. In short, media agencies or publishers can accept anything, but in UAE they are bound by religious and cultural values to a great extent. With this objective,many agencies have senior managers who make decisions related to advertising content that match with the values upheld by UAE. In sharp contra-distinction, the managers' job performance and rewards are linked to the overall profitability of the media organization, which is highly dependent on the earnings from advertisements. Hence they need to ensure that they attract the audiences as well as the advertisers as a vehicle to carry messages to the audience (Hayes and Rotfeld 1989).

Advertising practitioners and academicians are becoming more aware of and concerned about the ethicality of advertisements (Reidenbach and Robin 1988) and advertising/marketing in general. In fact, in the past decade participation in workshops, training seminars, and academic research onethical dilemmas in marketing has increased (Zinkhan, Bisesi and Saxton 1989).

There is an overall self regulation that is being practiced by the three actors of advertising self governance in United Arab Emirates. The advertiser or client, the advertising agency or producers of advertisements and the media print, online, audio and visual are working together in the process. There is greater responsibility for the advertisement on the media in the advertising agencies. Hence they are very careful in self-regulating the content of messages that go to a highly religious oriented culture in the UAE. According to Hemphil (1992), self-regulation exists when a firm, or industry or the business community establishes its own standards of behavior where no such statutory exists or when such standards assist in complying with or exceeding existing or regulatory requirements. Many such discussions about self-regulation exist in literature. It is also important to note that "Without the threat of government action, only the most altruistic of firms would ever pay heed to self-regulation directives" (Lacher and Rotfeld 1994). Hence the role of the National Media Council in UAE is important for advertisement regulation, although in most cases, an advertisement comes under scrutiny when a complaint is brought to the notice of the National Media Council. Hence the mechanism of self-governance is enforced by advertising agency and media to ensure their protection. Furthermore, contractual obligations made between client or advertiser and advertising agencies are important for the protection of advertising agencies if any legal action comes up against the advertising agency. Here the clause or article of the National Media Council states that it can shut down or close down the advertising agency if a negative message come from them. Media can also face legal actions if they do not take care of the cultural, legal and socio political nuances of the country while broadcasting any noncompliance material through the medium.

On the whole it can be concluded that there is a high amount of self-regulation that is happening at the client end, advertising agencies and the media end. These three actors together try to define the extent to which a message or content can be ethical or unethical within the dimensions of their survival as an organization entity. It is important to have an industry wide regulation as the world has become so global and advertisements transcends from one part of the world to the other through online and satellite communications. Wotroba (1997) proposes self- regulation as an industry level economic activity, as distinct from the micro level of the individual company or the macro level of all business in general and business activities in total. Traditionally, self-regulation has been employed by organizations to preempt, complement, or even replace public regulation (Garvin 1983). At the global level, selfregulation offers an opportunity for its proponent organization to advocate ways of reconciling among inconsistencies or incompatibilities in the rules and expectations of various countries. If done effectively, selfregulation might influence even governing authorities to sanction the self-regulation standards of conduct as public policy in United Arab Emirates as well. 


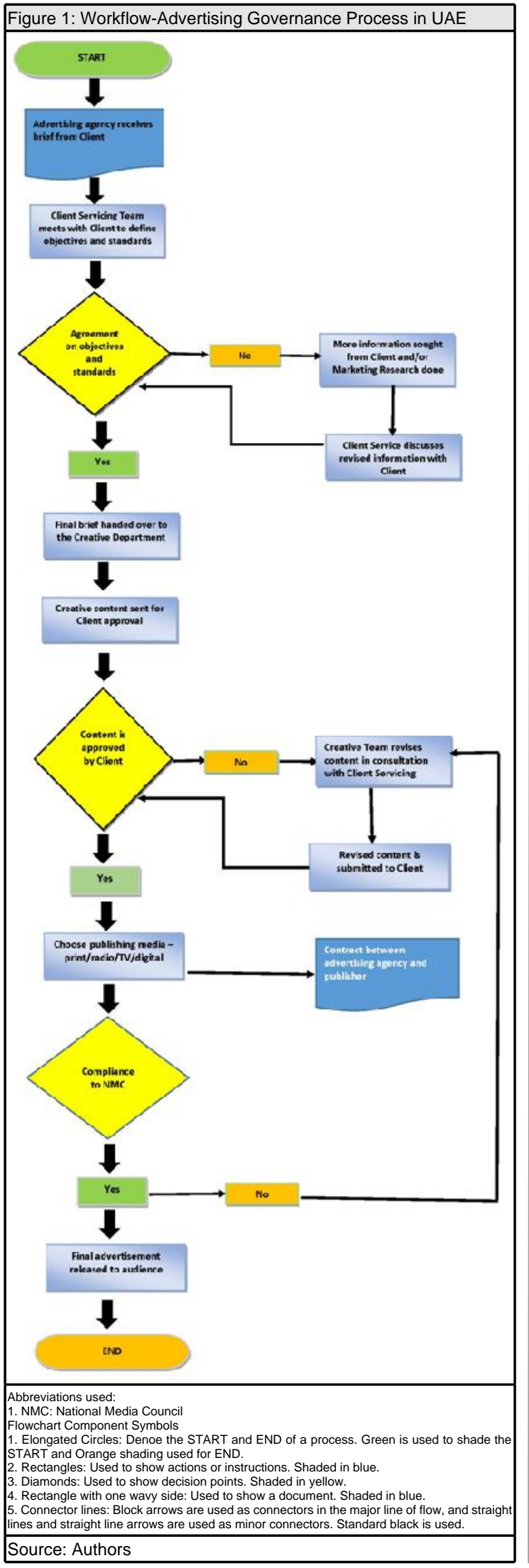

\section{REFERENCES}

Al Tamimi, (2013) Available in http://www.tamimi.com/en/magazine/ law-update/section-6/september-2/advertising-regulations-in-theuae.html\#sthash.6z9hov9r.dpuf, accessed on May 52015.

Ambwani (2015, June). ASCl's goal to promote self regulation and keep regulatory body away. Interviewer- A. R. Choudhury, Interviewer; India Television, Mumbai. June1. Retrieved from http://www.livemint.com/Consumer/r2fjfUYoC2IGOD5y6Nwndl/Digi tal-media-is-ASCls-biggest-challenge-says-Narendra-Amb.html

Arens, Williams F. (1996). Contemporary Advertising. USA: Richard D. Irwin, A. Times Mirror Higher Education Group Inc. Company.

Bennet, D. (2000). American culture and advertising. Monye, S.O. $(E d)$. The handbook of international marketing communications. Oxford: Blackwell.

Boddewyn, J. J. (1985). "Advertising Self-Regulation: Private Government and Agent of Public Policy," Journal of Public Policy and Marketing, 4, 129-141.

Cheng, H. (1996). "Advertising in China: a socialist experiment". In Frith, K. (Ed). Advertising Asia (pp. 73-102). Ames: lowa State University Press.

Dunn, S.W. and A. Barban. (1987). "Advertising, It's Role in Modern Marketing Advertising, Its Role in Modern Marketing". Hindsdale, Illinois, U.S.A.: Dryden Press.

Etzel, M.J., Walker, B. J.\& Stanton,W. J. (1997). Marketing. USA: Irwin/Mc-Graw Hill.

Frith , Katherine Toland \& Frith, M. (1990). "Western advertising and eastern culture: A confrontation in south east asia". Current Issues and research in advertising 12 (1-2), 63-73.

Garvin, David A. (1983). "Can Industry Self-Regulation Work?" California Management Review, 25 (Summer), 37.

Gulf News (2014). Bullish continues for UAE's Ad Spend. Retrieved from http://gulfnews.com/business/sectors/media/bullishrun-continues-for-uae-s-ad-spend-1.1328783 accessed on April 20 2015.

Haque, Ahasanul, Ahmed, Khaliq \& Jahan, S. I., (2010), " Shariah observation: advertising practices of Bank Muamalat in Malaysia" Journal of Islamic Marketing, Vol. 1, 1, 70-77.

Hayes, Rader, \& Rotfeld, Herbert J. (1989), "Infomercials and Cable Network Programming," Advancing the Consumer Interest, 1 (2), 17-22.

Hemphill, Thomas A. (1992), "Self-Regulating Industry Behavior: Antitrust Limitations and Trade Association Codes of Conduct", Journal of Business Ethics, 11 (December), 915-20.

Issac, J. (2013). UAE accounts for $33 \%$ of $\$ 4.8$ billion GCC ad sepend, Khaleej times June 6 2013. Retrieved from http://www.khaleejtimes.com/biz/inside.asp?xfile=/data/uaebusines s/2013/June/uaebusiness June105.xml\&section=uaebusiness, accessed on May 12015.

Kotler, P. (1988), Marketing Management: Analysis, Planning and Control, Prentice-Hall , Englewood Cliffs, NJ.

Lacher, Kathleen T., \& Rotfeld, Herbert J. (1994), "Newspaper Policies on the Potential Merging of Advertising and News Content," Journal of Public Policy and Marketing, 13 (Fall), 281-289.

Laczniak, R. N., DeCarlo, T. E., \& Ramaswami, S. N. (2001). 'Consumers' responses to negative word-of-mouth communication: An attribution theory perspective". Journal of Consumers Psychology, 11, 57-73

Louisa, Ha. (1996). "Concern about advertising practices in a developing country. An examination of china's new advertising regulations". International journal of advertising, 15, pp. 91-102.

Morden, A.R. 1991. Elements of Marketing. London: D.P. Publication Ltd.

Miracle, Gordon E., \& Nevett, T. (1987). "Voluntary regulation of advertising: A comparative analysis of united kingdom and united states". Published by Lexington Books.

Pollay, Richard W. (1986), "The Distorted Mirror: Reflections on the Unintended Consequences of Advertising, "Journal of Marketing," Vol 50, Issue 2.P- 18-36. 
Reidenbach, R. Eric \&Robin, D. (1988), "Some Initial Steps Toward Improving the Measurement of Ethical Evaluations. Journal of Business Ethics, 7 (November), 871-879.

Siassos, S.\&Saleem, S. (2013) Advertising standards for UAE. Retrived from http://www.tamimi.com/en/magazine/law-update/ section-5/february-4/advertising-standards-for-the-uae.html accessed on April 122015.

Singh, J. (1998) "Consumer complaints intentions and behavior: definitional and taxonomical issues". Journal of Marketing 52, 93-107.

Wotruba, T. (1997). "Industry self-regulation a review and extension to the global setting Journal of public policy and marketing". Vol. 16 No. 1, spring.

Wells, W., Burnett, J., Moriarty, S. (1994). Advertising Principles and Practice. 4thed. Prentice-Hall, Inc., Englewood Cliffs, NJ.

Zinkhan, G., Michael, B., and Saxton, M. J. (1989), "MBAs' Changing Attitudes Toward Marketing Dilemmas:1981-1987," Journal of Business Ethics, 8 (December), 963-974. 